\title{
Editorial
}

\section{Consent issues in cardiology}

The era of "benign paternalism" is over. Clinicians are now required to ensure the active participation of individual patients in decisions relating to their treatment, and their education regarding risks and benefits of diagnostic and therapeutic interventions. Except in those rare cases where disclosure of risk is likely to cause serious harm, clinicians must now attempt to ensure that patients are fully informed.

The obtaining of appropriately informed and well documented consent helps the process of developing trust between patient and clinician. Of developing importance is the defensive role played by the same process, when distressed or litigious patients suffer significant complications; this is especially so where outcomes involve serious long term consequences. In these cases, defective or inadequately documented consent procedures may provide relatively straightforward routes to successful claims. To succeed in law, claimants may have to do no more than demonstrate, on a balance of probability, that they have not been adequately counselled, and that had they been so counselled, they would not have undergone the procedure in question. While this represents a formidable hurdle in the case of urgent intervention such as life saving surgery for cyanotic congenital heart disease, it is one more easily surmounted in the case of elective procedures such as diagnostic cardiac catheterisation.

It is important to note that in certain circumstances a patient may provide only limited consent. For example, a patient may consent to coronary angiography but specifically refuse angioplasty. A patient may consent to major surgery but clearly reject the transfusion of blood or blood products. Clinicians agreeing to proceed under such restrictions must respect the patient's wishes. Except for measures that are both unforeseen and necessary in order to save life or prevent irreversible damage, no additional measures may be taken without obtaining consent beforehand.

\section{Obtaining valid consent}

For consent to be valid, three elements must be satisfied. The act of consenting must be wholly voluntary, the patient must be capable of understanding the nature of the proposed treatment, and must be provided with sufficient information about the treatment to know what he or she is accepting. Voluntariness rarely causes difficult problems in practice. The question of an individual patient's capacity is of greater practical importance, and can appear complex; however, it is the subject of clear precedent rules and decisions to which all clinicians should have ready access, ideally in the form of a regularly revised hospital consent policy. In hard cases it is wise to seek medicolegal advice. The adequacy or otherwise of risk disclosure is the least clear element of valid consent. It is in this area that clinicians are most in need of clear guidance, and where such guidance is least easily obtained.

Best practice dictates the provision to all patients of relevant information about proposed treatments (including any alternatives), in ways that can be understood. This information should contain an estimate of the relative risks and benefits of proposed treatments, and should be sufficiently detailed to enable patients to arrive at a balanced judgement, having had the opportunity to put their own value on the relative risks and benefits described. When advising patients as to their recommendations for treatment, clinicians should normally give their reasons; they should also provide sufficient information to enable patients to understand the nature, consequences, and any substantial risks involved. In imparting information, care should be taken to discuss the balance of risks- the risk of accepting treatment against the risk of refusal, including evidence that the proposed treatment will be of benefit.

When deciding how much information to give, it is wise to start from a premise that patients wish to be well informed. Occasionally, in the case of a particularly frightened or susceptible patient, a clinician may reasonably decide that some information should be withheld. However, for such a decision to be reasonable, appropriate measures should be taken to allay anxiety, through careful explanation, and where appropriate, counselling. In this context, it is arguable that a patient could not reasonably be described as "susceptible" in the absence of documented psychological or psychiatric problems. Where subsequent disputes arise, courts will most easily be persuaded by a clear contemporaneous recording in the patient's clinical records of decisions relating to disclosure of information, and the reasons which applied.

\section{Disclosure of risk}

The extent of the duty to disclose risk has until now been poorly defined in law. The doctrine of informed consent, long accepted in some jurisdictions, mandates the disclosure of those risks which a prudent patient would wish to consider, except where therapeutic privilege allows the withholding of information where disclosure would be injurious to the patient's health. ${ }^{1}$ In English law clinicians have been required to counsel their patients in a way recognised by their peers as appropriate. Disputes relating to consent have hitherto been decided on the Bolam principle; consent is valid where obtained "in accordance with a practice accepted by a responsible body of medical men". ${ }^{2}$

However, just as allegations of negligent treatment are now subject to the caveat in the 1998 Bolitho judgment, whereby peer endorsement is subject to logical analysis by a court, so too are decisions relating to risk disclosure and consent. ${ }^{3}$ This is clear from the carefully worded judgment in the Court of Appeal decision Pearce $v$ United Bristol Healthcare NHS Trust. ${ }^{4}$ This recent case, not yet widely reported, and whose significance remains underrecognised, is a decision of Lord Woolf, one of the most senior members of the judiciary, and architect of the radical overhaul in 1998 of the procedures for conducting civil litigation. Lord Woolf unambiguously explains his decision in Pearce as the practical application of the Bolitho judgment to the Bolam principle. ${ }^{5}$ It is therefore the first authoritative decision showing how the two leading House of Lords decisions will operate in the area of consent, and arguably accepts into English law the "reasonable patient 
test" and the doctrine of "informed consent". Although perhaps under appreciated in legal circles, since it does not overturn any precedent decisions, Pearce is of importance to clinicians, as it advises precisely what is now expected of them:

" if there is a significant risk which would affect the judgement of a reasonable patient, then ... it is the responsibility of a doctor to inform the patient of that risk if the information is needed so that the patient can determine ... what course he or she should adopt".

As a result of the precedent case of Sidaway, clinicians routinely disclose any significant complication occurring at a rate of $1 \%$ or greater, and discuss in all cases those complications as serious as death or neurological damage, no matter how low the rate of occurrence. ${ }^{6}$ Pearce makes it clear that clinicians must now go on to ask: "is there a significant risk which would affect the judgement of a reasonable patient in this situation, which has not been disclosed, and which the patient should know so that he or she can determine what course to adopt?" Finally, although existing legal guidance fails to make this clear, best practice must ensure that even remote risks are recognised as important, and therefore disclosed, where the interests or vocation of an individual patient make this appropriate.

\section{How are cardiologists and cardiac surgeons affected?}

How do these requirements affect cardiologists and cardiac surgeons? Two points are worthy of consideration. Firstly, given the relatively sophisticated judgement regarding risk disclosure that will inevitably be required on a regular basis, the formal process of obtaining consent should not be delegated to any member of a clinical team without the experience of performing the procedure in question. Secondly, the greater effort required of patients to assimilate and process risk information mandates its early and clear dissemination. Risk information is best given out before the date of admission for elective procedures, with time reserved on admission for answering questions, and for the important process of ensuring that patients' personal risk factors remain unchanged. This can be of help to the clinical team, who will better be able to concentrate on positive outcomes when the patient is admitted, and of benefit to the patient who can resolve doubts and queries before admission, using the resources of preadmission clinics and cardiac liaison nurses. Risk information should be made available in written form, as there is some evidence that when given spoken risk information preoperatively, patients have good recall of mortality risks, but only a moderate recall of risks of morbidity. ${ }^{7}$

New problems will arise, and cardiac surgeons and cardiologists may expect to remain in the public eye over risk disclosure. The availability of outcome data for cardiac surgery, and increasingly for interventional cardiology, will ensure that patient expectations regarding accurate and appropriate risk disclosure will remain high in these areas. However, there remain situations where risk disclosure is complicated by the circumstances in which the procedure is offered. For example, when parents of neonates requiring immediate lifesaving cardiac surgery are offered risk information, it is inevitable that there will be difficulties in ensuring proper appreciation of risk. Clinicians are advised to document most carefully the discussions held with parents at such times. Even in the less challenging situations of adult elective procedures, patient expectations are not uniform. It may not be practicable to continue to accommodate the wishes of patients who decline risk information, while consenting to the procedure in question. The words "do what you think best, Doctor" may in future pose as many problems as they solve.

NIGEL W BERESFORD

Senior Advisor in Clinical Risk,

Royal Brompton Hospital,

Sydney Street,

London SW3 6NP, UK

n.beresford@rbh.nthames.nhs.uk

No conflict of interest. Supported by the Clinical Research Committee of the Royal Brompton \& Harefield NHS Trust

1 Rogers $v$ Whittaker (1991) 23 NSWLR 600.

2 Bolam v Friern Hospital Management Committee (1957) 2 All ER 118. 3 Bolitho v City \& Hackney HA (1998) 9 MLR 26 (HL)

4 Pearce v United Bristol Healthcare NHS Trust (1999) PIQR, (CA).

5 "Are the courts excessively deferential to the medical profession?" Rt Hon Lord Woolf, Lord Chief Justice of England and Wales, provost's lecture series, Shaping the future, University College London, 17 January 2001.

6 Sidaway v Governors of the Bethlem Royal and Maudsley Hospital (1985) AC 871.

7 Seymour L, Woloshynowych M, Adams S. Patient perception of the risk associated with elective heart surgery. Healthcare Risk Resource 2000;3:811. 